\title{
ESTRATEGIAS PARA LA COHABITACIÓN A PARTIR DE LOS ESPACIOS COMUNES Articulaciones proyectuales a través del análisis de casos en Rosario, Argentina
}

\author{
Víctor Franco López \\ Universidad de Buenos Aires \\ Director tesis doctoral: Fernando Néstor Murillo / Co-Directora: Lorena Vecslir \\ E-Mail: victorfrancolopez@gmail.com
}

\section{RESUMEN}

Entendiendo a las ciudades como partes interrelacionadas de un territorio con el que debemos operar, el objetivo general del presente trabajo sería proponer pautas de adecuación y densificación a partir de la ciudad existente que, partiendo del análisis y reinterpretación del tejido urbano-habitacional de algunos casos de estudio en Rosario, puedan proyectar escenarios alternativos a los del Estado y el mercado. Así, a partir del paradigma de lo común y lo relacional, se plantea realizar algunas propuestas posibles de diseño y planificación del desarrollo urbano en torno a los lineamientos que marca la Nueva Agenda Urbana consensuada en el acuerdo de Quito en Hábitat III en 2016. Se abordarán algunos aspectos, tales como el derecho a la ciudad, la auto-organización comunitaria, las redes municipales, la alianza público-ONG-comunitario o la densificación de centros, siempre intentando conciliar la cuestión del desarrollo sustentable tanto en términos sociales, como económicos, culturales y ambientales.

Palabras clave: Nueva Agenda Urbana - procomún - cohabitación - espacios comunes

\begin{abstract}
Understanding cities as interrelated parts of a territory with which we must operate, the general objective of this work would be to propose patterns of adaptation and densification from the existing city that can project alternative scenarios to those of the State and the market, starting from the analysis and reinterpretation of the urban-housing fabric from some examples in Rosario. Thus, from the paradigm of the common and the relational, it's proposed to make some possible proposals for the design and planning of urban development around the guidelines established by the New Urban Agenda agreed in the Quito agreement in Habitat III in 2016. Some aspects will addressed, such as the right to the city, the community self-organization, the local networks, the public-NGOcommunity alliance or the densification of centers, always trying to reconcile the issue of sustainable development in social, economic, cultural and environmental terms.
\end{abstract}

Key words: New Urban Agenda - commons - cohabitation - common spaces 


\section{CRISIS SISTÉMICA Y LA NUEVA AGENDA URBANA}

Las crisis sistémicas reiteradas que vivimos, que son el sustento del propio sistema capitalista, y el momento de revuelo geopolítico actual, con las denominadas "crisis energética", "crisis alimenticia", "crisis urbana", etc. se hacen presentes cada vez más en todos los contextos. Los mercados financieros globalizados y deslocalizados desdibujan los límites políticos y afectan cada vez más a un número mayor de habitantes alrededor del mundo. Temas como la informalidad, la desigualdad, los movimientos migratorios, los desastres naturales, el cambio climático... afectan cada vez más a la vida urbana en el planeta.

En este sentido, las ciudades contemporáneas presentan múltiples disfunciones a nivel de movilidad, habitabilidad, espacios públicos, acceso a servicios, seguridad, contaminación, etc. El paradigma de la planificación urbana queda así en crisis, provocando numerosas preguntas: ¿a qué modelo de ciudad estamos tendiendo? ¿Es sustentable esta tendencia? ¿Las ciudades actuales satisfacen las necesidades de sus habitantes? ¿Deseamos que en el futuro el desarrollo urbano siga los modelos actuales?

Cabe destacar que los asentamientos humanos, especialmente en las ciudades, son factores claves en las complejas ecuaciones cuyas premisas son el crecimiento y el desarrollo, los problemas ambientales, los derechos humanos y la erradicación de la pobreza, y deberían ser estudiados a partir de nuevas concepciones revolucionarias en busca de un urbanismo más humano (Harvey, 1977: 330). Este fue el gran desafío de la conferencia mundial del hábitat (Hábitat III) que se llevó a cabo el 2016 en Quito, donde se lograron generar acuerdos mínimos comunes bajo el lema "Desarrollo Urbano Sostenible: el futuro de la urbanización".

Frente a esta situación de crisis urbana, esta cumbre global generó un documento con lineamientos generales, que los diferentes países firmantes del acuerdo deben implementar, denominada la "Nueva Agenda Urbana". Este documento servirá de guía sobre temas de hábitat para los próximos 20 años previos a la celebración de Hábitat IV. Algunos de los temas consensuados en la cumbre y que sirven se abordan en el presente trabajo serían el derecho a la ciudad, la auto-organización comunitaria, las redes municipales, la alianza público-ONG-comunitario y la densificación de centros creando múltiple oferta social.

Para ello, el estudio de experiencias a partir de concepciones alternativas en busca de un urbanismo más humano parece clave para responder a dichos planteos. En este sentido, día a día son implementadas múltiples intervenciones sobre los espacios comunitarios por iniciativa vecinal en nuestras ciudades. Dichas intervenciones, al surgir de la propia ciudadanía, suelen tener un fuerte carácter participativo y responden a las necesidades de la comunidad en un momento determinado. Estas acciones colectivas tienen como elementos clave a la participación, el intercambio, la ayuda mutua y la co-construcción, pudiendo representar un mecanismo de transformación urbana alternativa. Así pues, se plantea que un nuevo paradigma urbano basado en el procomún, la ciudad relacional y el código abierto podría ofrecernos caminos posibles para hacer frente a nuestras insustentables, injustas y desiguales ciudades contemporáneas.

\section{CIUDADES COMUNES}

Sin duda, lo que se viene imponiendo es la idea de transformación radical de nuestras insostenibles ciudades modernas y nuestras formas de vivirlas. Parece que una de las claves de los enfoques territoriales acerca de la construcción de una ciudad sustentable sería la del reciclaje de las mismas ciudades, sin necesidad de construir otras nuevas o, por lo menos, el análisis y reinterpretación del tejido urbano existente en ellas. Así, se plantean algunos interrogantes al respecto: ¿podría surgir de nuestras ciudades existentes el impulso necesario para una transformación radical de la civilización dominante?

Por un lado, focalizar la mirada en la ciudad existente con el objetivo de encontrar claves propias capaces de evolucionar en el tiempo es algo que el ser humano siempre hizo a la hora de transformar sus propios hábitats. Recuperar el papel de la vivienda en la ciudad puede proporcionar nuevos enfoques en la reflexión acerca de un urbanismo más sostenible, puesto que la vivienda popular, como ejemplo de producción social del hábitat, "nos permite evaluar la relación entre las formas de habitar y la sociedad contemporánea, así como estudiar nuevas formas de eficiencia económica, ambiental y social” (Sáez; García; Roch, 2010). 
Por otro lado, en realidad, para posibilitar un cambio real, se puede decir que no es una cuestión de tener o no tener el poder, sino de actuar posibilitando "un nuevo tipo de política centrada en los nuevos tipos de actores políticos" (Sassen, 2001: 19). En este sentido, el paradigma de las "ciudades comunes", como parte de un proyecto más amplio de democracia directa, podría crear al mismo tiempo relaciones humanas fuertes basadas en la solidaridad y la participación. Así, la construcción colectiva de un entramado de redes comunitarias de las denominadas "ciudades comunes" pretendería fomentar el empoderamiento ciudadano y las prácticas colectivas para con el fin de alcanzar el derecho urbano de las ciudades del siglo XXI (Franco, 2016a).

\subsection{Derecho a la ciudad y a la arquitectura}

La tarea política de organizar esta confrontación contra el sistema dominante resulta difícil, pero no apabullante. En realidad, actualmente las oportunidades al respecto se multiplican, puesto que las crisis y las luchas estallan tanto local como globalmente. Dar un paso adelante en este sentido para unificar estas luchas supone adoptar el derecho a la ciudad como eslogan práctico e ideal político, donde "la democratización de ese derecho y la construcción de un amplio movimiento social para hacerlo realidad son imprescindibles si los desposeídos han de recuperar el control sobre la ciudad del que durante tanto tiempo han estado privados, y desean instituir nuevos modos de urbanización" (Harvey, 2008: 38-39).

Con la idea de aportar a la espacialización de un posible nuevo rol de las ciudades, la creación arquitectónica que, debido a la fragmentación de la praxis humana bajo el efecto de la división capitalista del trabajo, tiende a especializarse y diversificarse en su propio seno y que está reservada a una minoría, como veíamos, debe asumir la complejidad y efectos de sus acciones. El hecho de que sólo unos privilegiados tengan la decisión acerca de la transformación del entorno en el que sus semejantes se ven obligados a vivir conlleva una ilegitimidad a partir del poder que ejerce sobre el imaginario de los habitantes (Garnier, 2006: 141). Así pues, la arquitectura tiene el deber de "democratizarse", puesto que está imbricada con lo social y ambiental y nos afecta a todos, especialmente aquello relacionado con lo urbano o común, y debemos trabajar para que la opinión sobre estos temas sean debatidos entre todos los implicados, dejando de tener únicamente las consultas populares un carácter consultivo, cuando las hay y no son manipuladas.

Además, aunque hoy en día ya la inmensa mayoría de la humanidad da por obvio y se legitima el derecho a la vivienda como un derecho humano, la vivienda sigue siendo más un privilegio que un derecho propiamente dicho. A pesar de las diferentes declaraciones de Naciones Unidas al respecto, la proclamación y su defensa en múltiples foros, asambleas y a través de organizaciones sociales, incluso su aparición en algunas Constituciones de países de América y Europa, parece no bastar para refrendarlo, puesto que "[...] las leyes y las prácticas jurídicas y las políticas públicas no consideran este derecho como ejercitable, no se reglamentan, se mantiene intocable el código de derecho civil, no se aplica ni se exige a jueces y a gobernantes aunque lo consideren un derecho. Es lo que se denomina "derecho programático", para que sea real depende de las políticas públicas y del mercado y solo tiene acceso a materializar este derecho o si tienen una demanda solvente o forman parte de una clientela política" (Borja, 2015).

\subsection{Sustentabilidad urbana}

Sin duda, uno de los mayores retos del urbanismo contemporáneo y futuro para llegar a la sostenibilidad urbana deseada, es la recuperación de la consideración del ámbito local, sepultado, como se ha visto, bajo el impulso de un pensamiento único. Éste se traduce, entre otras cosas, en una economía global, en una ética común del entretenimiento con una sociedad del espectáculo como escenario, y en formas y arquitecturas genéricas que contribuyen a la despersonalización de los asentamientos humanos. Para evitarlo, es necesario proponer alternativas trabajando con referencias territoriales, de identidad, de relación con el clima, la cultura tradicional, las formas y materiales autóctonos y, sobre todo, que tengan en cuenta la participación e implicación real del ciudadano. En este sentido, se plantea que las posibles soluciones han de poder encontrarse en la propia ciudad, no en soluciones externas, sino fruto de la propia sabiduría popular, la cultura y la sociedad de cada lugar particular. Existen buenas soluciones a la hora de hacer ciudad en la propia ciudad, cosa que hace necesaria la revalorización de lo existente como alternativa a adoptar soluciones foráneas. Pero esto sólo será posible si el urbanista del siglo XXI atiende a la vida real de los usuarios de la ciudad, a la vida de todos los días. Y ello, por 
supuesto, sin dejar la visión compresiva y global del hecho urbano y las aproximaciones más analíticas y abstractas a su funcionamiento.

Cabe destacar que el lineamiento de compacidad urbana postulado dentro de la Nueva Agenda Urbana, refuerza y confirma múltiples estudios que durante los últimos tiempos apuntan a una densidad media como un punto de equilibrio en el que, por un lado, se optimiza el abastecimiento de servicios y, por otro lado, se facilita la creación de un tejido social coherente (escala humana, espacios de socialización, etc.). Además, los crecimientos de densidad media permiten la mezcla de usos que hacen sustentable la existencia de pequeños comercios y equipamientos, disminuyendo la dependencia a zonas de mayor centralidad, todo ello con más respeto por el medio ambiente, posibilitando al mismo tiempo un tipo de asentamiento territorial más coherente con su entorno. Es importante indagar, entonces, acerca de los umbrales de densidad y compacidad que puedan facilitar este tipo de vida urbana y relaciones sociales deseables. La relación entre ocupación del suelo, altura y densidad serán los indicadores clave, así como la mixicidad, la multiplicidad y la diversidad, tanto de espacios, como de usos y actores involucrados.

En cuanto al tema de la vivienda en particular, a la hora de repensar el habitar contemporáneo, es importante el hecho de plantearse el sentido político que tiene la arquitectura de la vivienda como hacedora de ciudad y como espacio de convivencia y crecimiento personal. Ella debe responder a la diversidad de la sociedad, contribuir a mejorar la calidad de la ciudad y el territorio, hacer un uso razonable y responsable de las tecnologías disponibles y responder a unos objetivos sostenibilistas, además de potenciar la diversidad, la heterogeneidad y la flexibilidad, al mismo tiempo que permite las funciones de producción y reproducción en su propia estructura y la variación y evolución espacial en el tiempo (Muxí, 2010).

\subsection{Redes comunitarias}

Frente a los grandes cambios sociales que venimos experimentando, las reiteradas crisis económicas, financieras y políticas, es necesario transformar las políticas públicas en general y las locales en particular. En este sentido, "podemos afirmar que el bienestar hoy va pasando de ser una reivindicación global para convertirse cada vez más en una demanda personal y comunitaria, articulada alrededor de la vida cotidiana y en los espacios de proximidad" (Subirats; Montaner, 2012), donde la vivienda colectiva y, en especial, el hábitat popular y sus espacios comunes podrían tener un papel fundamental a la hora de repensar el habitar contemporáneo y sus relaciones políticas y económicas.

Este derecho es mucho más que la libertad individual de acceder a los recursos, sino que se trata del derecho a cambiarnos a nosotros mismos cambiando nuestro entorno y depende inevitablemente del ejercicio de un poder colectivo para remodelar estos procesos.

La fuerza que puede permitir el municipalismo ${ }^{1}$ y el comunitarismo ${ }^{2}$ como escala de proximidad a la realidad ciudadana y el trabajo en red de poderes locales que se viene constituyendo como una verdadera alternativa donde "lo hiperlocal se va reconectando poco a poco globalmente en un nuevo ecosistema planetario en el que las súper estructuras que representan a los Estados nación tienen cada vez menos influencia en la política" (Gutiérrez, 2016: 3). ¿Cuál debe ser entonces el modelo de ciudad para siglo XXI?

Si entendemos entonces que el espacio se construye a través de relaciones sociales, podemos reconocer la construcción relacional de nuestras identidades personales. Se vuelve imprescindible el encuentro con otros sujetos, puesto que somos, esencialmente, seres sociales en permanente interacción. Como plantea lgnaci de Solà-Morales (2009), el ser urbano, más allá de poder estar desolado por la velocidad con la que el mundo se transforma a nuestro alrededor, está necesitado de convivir con los otros, con el otro. Estos espacios de intimidad representan la dimensión de lo múltiple de la vida cotidiana, al mismo tiempo que influyen en nuestros imaginarios

\footnotetext{
${ }^{1}$ El municipalismo es el paradigma político que permite la canalización de movimientos masivos de luchas en plataformas ciudadanas con capacidad de articular colectivos diversos, donde interactúan lo real y lo virtual. Representa la irrupción de la "gente común" en las instituciones y busca transformar radicalmente el panorama de la política de proximidad, articulando las dimensiones tanto física como digital, y potenciando el trabajo en red (Franco, 2016b).

2 El comunitarismo representa una de las tradiciones con mayor influencia en la filosofía política contemporánea. En contraposición a la tradición liberal, el comunitarismo defiende una idea común del bien, como crítica al individualismo y a la neutralidad estatal (Santiago, 2010).
} 
y nuestras actitudes políticas. Por este motivo, el estudio de estos "espacios comunes" parece significativo desde el punto de vista de la escala de proximidad, donde se gesta lo personal y lo comunitario.

Así, se plantea el análisis y la reflexión acerca de una ciudad relacional que podría permitir formas de cohabitar basadas en el encuentro, la relación de vecindad y el diálogo. Este nuevo ecosistema tiene a la ayuda mutua, los cuidados y el compartir como su ADN y a la vivienda colectiva como su representación simbólica de mayor proximidad.

\section{CONOCIMIENTO ABIERTO}

Con la idea de brindar herramientas útiles, coherentes y contemporáneas para el empoderamiento social y frente al paradigma del diseño de autor, la fragmentación del conocimiento y la elitización de los saberes, cada vez emerge con mayor fuerza la idea del co-diseño como una manera de democratizar su acceso y su uso de manera colaborativa. El copyleft y el creative commons representan esta tendencia hacia la catalización de sinergias colaborativas como un nuevo paradigma emergente.

La arquitectura como disciplina todavía se resiste mayoritariamente a esta tendencia, puesto que cambia la manera en la que se viene desarrollando la profesión durante mucho tiempo. El hecho de democratizar el acceso al diseño urbano-arquitectónico permite pensar maneras alternativas de transformar nuestros entornos de manera comunitaria. Así, la recopilación de datos surgidos a partir de la inteligencia colectiva situada en el territorio podría representar una metodología necesaria hacia la sustentabilidad urbana.

La Universidad pública como espacio potencial de articulación entre investigación-experiencia-acción debería suponer un escenario ideal para la puesta en práctica de estas ideas con el objetivo de fomentar conocimiento académico, transdisciplinar y abierto capaz de investigar para mejorar la vida de la sociedad. Debería ser importante encontrar coherencia entre el objetivo de estudio propuesto y las necesidades socio-espaciales contemporáneas, para intentar darles respuestas de manera inminente. Ante la crisis urbano-ambiental que nos apremia, el cambio climático, la desigualdad, la pobreza, el ritmo frenético de urbanización en muchos lugares del mundo, junto con el extractivismo, la explotación y la especulación, hace que sea urgente un cambio de paradigma en la manera de conceptualizar, investigar y desarrollar la arquitectura y el urbanismo contemporáneos, que tenga como objetivo principal la búsqueda de la justicia social, la equidad y la inclusión. La Universidad pública debería ser ejemplo de vanguardia en el estudio de alternativas ante esta situación.

En este sentido, la tesis de doctorado, donde se inscribe el presente trabajo, que se viene desarrollando en la FADU-UBA bajo el título "La Ciudad Común: la vivienda popular colectiva como germen de una urbanidad alternativa desde el territorio latinoamericano", pretende abordar posibles propuestas alternativas urbanohabitacionales que puedan tener a la ayuda mutua como eje proyectual a través de sus espacios, usos y gestiones comunes. Para ello, se viene haciendo un relevamiento de casos donde se empieza a trabajar la aplicación del paradigma de "lo común"3 en la arquitectura y el urbanismo.

Por el momento, se comenzó con este trabajo durante la primera edición de una materia optativa en la Facultad de Arquitectura, Planeamiento y Diseño de la Universidad Nacional de Rosario titulada "Arquitecturas de lo común y formas de habitar el presente". El análisis de casos construidos en la misma ciudad permite, por un lado, generar nuevo conocimiento académico al estudiar casos inéditos y al recopilarlos dentro de un mismo proyecto de investigación. Por otro lado, permite poner en valor la arquitectura local y la inteligencia colectiva situada, fomentando el estudio y la preservación del patrimonio construido, desde donde debería partir cualquier proyecto de arquitectura. Además, permite pensar y poner en práctica criterios de análisis y representación de "lo común" en la arquitectura.

\footnotetext{
${ }^{3}$ Según Christian Laval y Pierre Dardot, "el término "común" designa, no el resurgimiento de una idea comunista eterna, sino la emergencia de una forma nueva de oponerse al capitalismo, incluso de considerar su superación. Se trata igualmente de un modo de volver la espalda definitivamente al comunismo estatal" (Laval; Dardot, 2014 [2015: 21]).
} 
Todo esto con el objetivo final de democratizar el acceso al diseño y proporcionar herramientas prácticas para su colectivización a partir de los espacios comunes, aquellos gracias a los cuales se pueden sentar las bases de los procesos participativos y de los acuerdos estructurantes del conjunto a partir de los que se desarrolla.

\section{ARQUITECTURAS DE LO COMÚN}

Como decíamos, se plantea que la Universidad pública sirva para pensar acerca del rol de los y las arquitectos/as y urbanistas en la sociedad contemporánea, la necesidad de adaptar el conocimiento a la sociedad y la democratización del acceso al diseño. Con este propósito, y para poner en práctica el planteo teórico-conceptual que se viene desarrollando en la tesis de doctorado, se inicia el segundo semestre de 2017 una asignatura optativa en la FAPyD-UNR titulada "Arquitecturas de lo común y formas de habitar el presente", dentro del Taller Bagnasco.

El objetivo principal de la propuesta de investigación colectiva es introducir a los y las estudiantes al paradigma de "lo común". Nos centramos en el estudio de espacios y usos comunes a partir de los cuales podemos pensar estrategias proyectuales para la vivienda colectiva contemporánea, haciendo especial atención a su potencialidad como articuladores para la inclusión y como herramientas para la construcción de imaginarios habitacionales alternativos de manera colectiva.

La propuesta de trabajo incluyó las siguientes pautas:

-Se introdujo a los y las estudiante al campo de la investigación, produciendo conocimiento inédito sobre los casos como base para su estudio, a través de planos históricos, entrevistas, fotografías, mapeos, etc.

-Se analizaron casos de estudio paradigmáticos de diferentes épocas y tipologías urbano-habitacionales de la ciudad de Rosario a partir de sus espacios comunes.

-Se reflexionó acerca de los registros obtenidos y se compararon los casos entre sí para todos y todas las estudiantes pudieran tener un conocimiento más amplio y transversal sobre el tema de estudio.

-A partir del material producido, se propuso experimentar mediante ejercicios proyectuales nuevas configuraciones formales de la vivienda colectiva para su adecuación a las necesidades contemporáneas y al paradigma de "lo común".

Durante el desarrollo de la materia se profundizó conceptualmente con lecturas de textos, debates colectivos y esquicios sobre la relación entre espacio y poder y sobre posibles alternativas de acceso al hábitat y de producción y gestión social de la vivienda. Algunos conceptos que revisamos fueron: Espacialidades de lo común, Ética hacker, Arquitecturas de código abierto, Modos de habitar el presente, Antipatriarcado, Hábitat inclusivo, Escala humana, Co-habitación, Ciudad relacional y cuidadora, Urbanismo colaborativo, etc.

El listado de casos analizados es el siguiente:

-Barrio Parque / Arqs. Hernández Larguía+Newton

-Conjunto en Oroño 44 bis / Ing. Eduardo Méndez

-Conjunto en Tucumán 1048 / Arq. Emilio Maissonave

-Conjunto en Pte. Roca 39 / Arq. Ángel Guido

-Barrio Latinoamérica / Fo.Na.Vi

-Edificio Guernica / Arq. Fernández Díaz

-Edificio N 1 de la Cooperativa de Vivienda de Rosario / Arq. Fernández Díaz 
-Conjunto Galería César / Arqs. Noguerol+Brebbia

-Conjunto Mandel 1 / Arzubialde Arquitectos

-Conjunto en Granadero Baigorria / Arqs. Beltramone+Costa+De La Horra

La elección de los casos responde a un criterio de variedad tipológica urbano-habitacional y de producción y gestión del hábitat, con el objetivo de producir conocimiento académico a partir de generar un repositorio de casos. Desde la tipología, tenemos tipo "PH" o "departamentos de pasillo", barrios de viviendas y grandes, medianos y pequeños conjuntos. En todos ellos podemos reconocer espacios y usos comunes como una dimensión a analizar a partir de la cual podemos extraer diversas claves proyectuales de articulación con lo existente, bien de adecuación y/o de densificación. El paradigma de "lo común" aplicado a la arquitectura exige una mirada nueva sobre el espacio, entrando en juego entre el binomio público-privado para entender y plantear nuestros entornos. También permite profundizar acerca de la relación intrínseca existente entre espacio y poder, cosa que plantea desafíos acerca del hábitat inclusivo, contra una mirada patriarcal, colonial y extractivista del espacio urbano.

En cuanto a la producción y gestión del hábitat, se ofrecen también ejemplos diversos. Por un lado, la construcción por parte del Estado, bien en formato de construcción de grandes conjuntos, a través de créditos otorgados por el Banco Municipal de Rosario o bien mediante el plan nacional Pro.Cre.Ar. Por otro lado, se plantea un modelo más de mercado (aunque todavía de ganancia distribuida) a través del fideicomiso. Y también se propone la producción y gestión de tipo comunitaria a través de cooperativas de vivienda. Esto permite poner en relación diferentes variables más complejas a la del espacio y el uso, con el objetivo de hacer propuestas que puedan tener un mayor impacto positivo transformador en el territorio.

\subsection{El pasillo como vínculo}

Como decíamos, una de las tipologías a analizar fueron los "departamentos de pasillo", hoy también denominados como "departamentos tipo casa" o más coloquialmente simplemente como "PH", que surgen a partir de un proceso de densificación en horizontal y como derivación de la denominada "casa chorizo" como medida de ancho de lote y tipología habitacional. Representando un mecanismo de densificación notable a principios de siglo, estos conjuntos habitacionales modificaron la estructura original de la "casa chorizo", de carácter individual, a viviendas colectivas, cuyas unidades habitacionales se relacionaban mediante un pasillo que funcionaba de estructurador del tejido hacia el interior de la manzana de forma horizontal (Franco, 2017a). Esto permitía el aprovechamiento de la profundidad de los lotes muy angostos y profundos, conformando tejidos de muy alta ocupación del suelo. Los pasillos podían ser de tipo lateral o central (figs. 1, 2 y 3). En el primero de los casos, la casa chorizo se situaba en la cabeza de la serie de unidades y tenía frente a la calle, dejando simplemente una puerta lateral de acceso al pasillo que permitía la distribución en profundidad a través del lote, dando paso a cada una de las unidades situadas en hilera. En el segundo caso, el pasillo conforma el eje de simetría del conjunto de forma espejada a los conjuntos de pasillo lateral. 


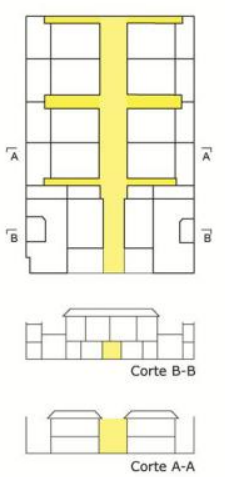

Espacios comunes

$\square$ Circulaciones/halles

$\square$ Patios
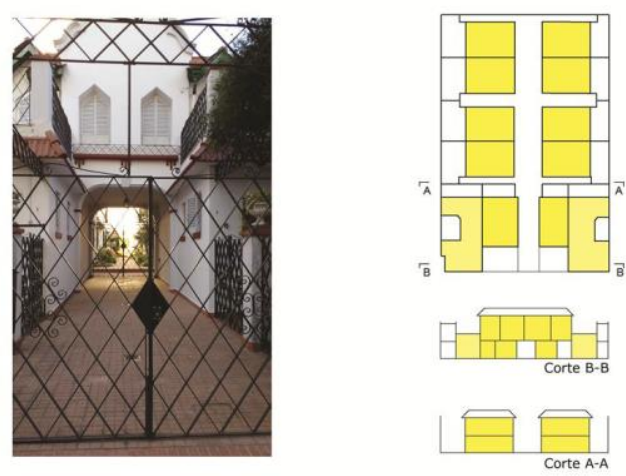

Plantas tipo

$\square$ Tipo A

$\square$ Tipo B

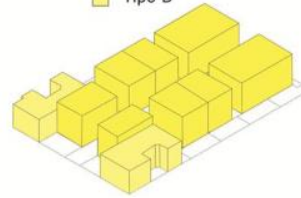

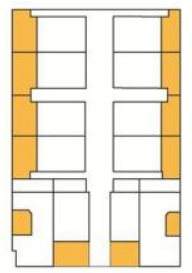

$\square$ Espacios exteriores vinculados a la vi-

Fig. 1. Conjunto en Pte. Roca 39 - Análisis espacios comunes y públicos: pasillo central Fuente: Camila Benítez, Clara Rovere, Camila Vila; AC-2017

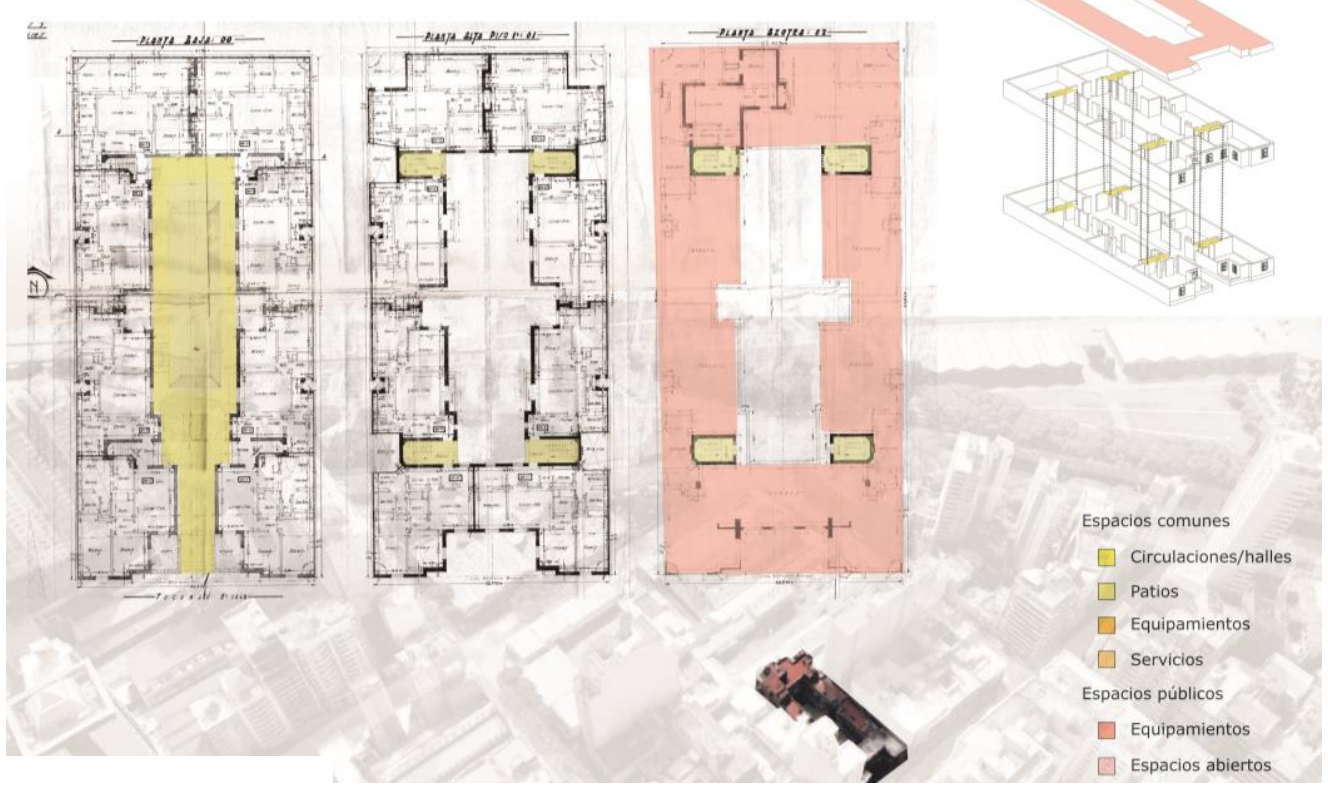

Fig. 2. Conjunto en Tucumán 1048 - Análisis espacios comunes y públicos: pasillo-patio central Fuente: Santiago Arias, Gastón Chaves, Germán Quinteros; AC-2017 


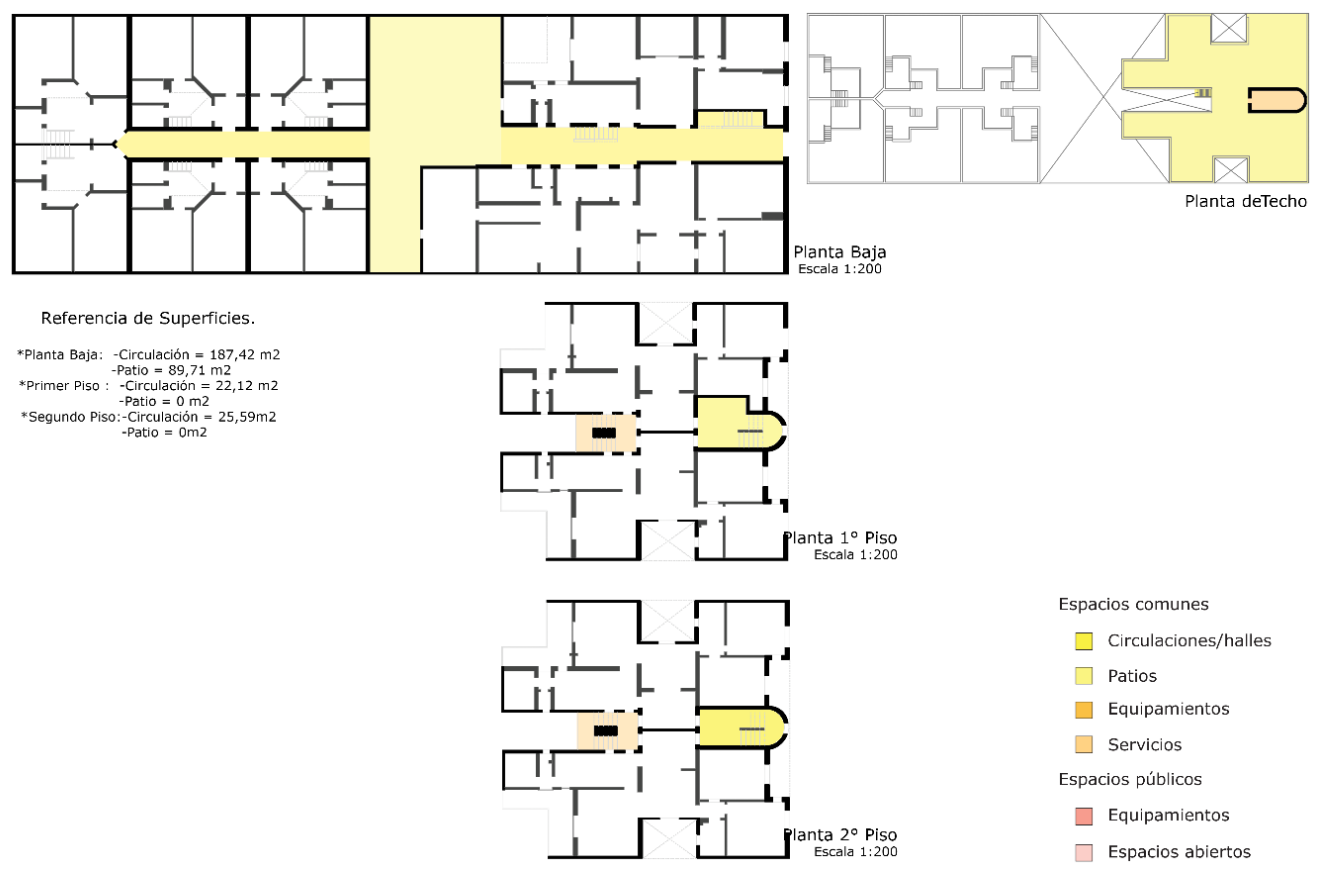

Fig. 3. Conjunto en Oroño 44 bis - Análisis espacios comunes y públicos: distribuidores

Fuente: Nahuel Ginart, Nicolás Zof; AC-2017

\subsection{Espacios de transición}

La primera conexión con lo público, más allá de lo íntimo, como primera escala de relaciones sociales, es aquella que se da en las viviendas colectivas, convirtiendo a sus espacios comunes como los espacios donde se ejerce la micropolítica, hacedora de ciudad y ciudadanía. Estos espacios comunes, como espacios intermedios o espacios "entre", serían aquellos capaces de poner en relación la escala de lo íntimo con la de lo comunitario y lo colectivo, permitiendo diferentes gradientes de transición. Así, estos espacios representan los recipientes de la memoria y del deseo colectivo, además de la imaginación social y geográfica que invita a nuestras relaciones y escenarios de posibilidades. Esta primera instancia más íntima y de escala reducida podría resultar un caldo de cultivo para la politización de la sociedad (Franco, 2017b). Además, pueden ser de carácter exclusivamente privado hasta los más públicos, pasando por posibilidades intermedias de semipúblicos o semiprivados. Más allá de los pasillos anteriormente citados, podemos encontrar espacios de circulación interna (figs. 4 y 5), como escaleras, rampas, palieres, distribuidores, zaguanes, etc., así como también externa (fig. 6 y 7): pasajes, calles, plazas... 


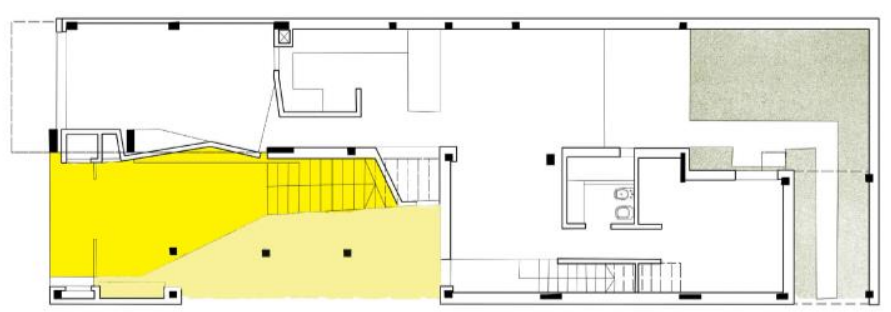

PLANTA BAJA
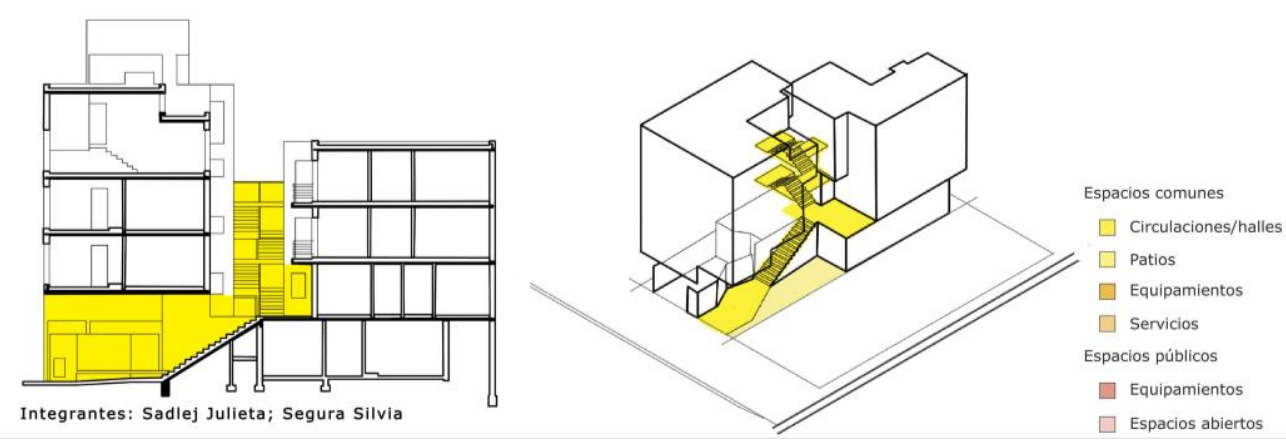

Fig. 4. Conjunto Mandel 1 - Análisis espacios comunes y públicos: escaleras

Fuente: Julieta Sadlej, Silvia Segura; AC-2017
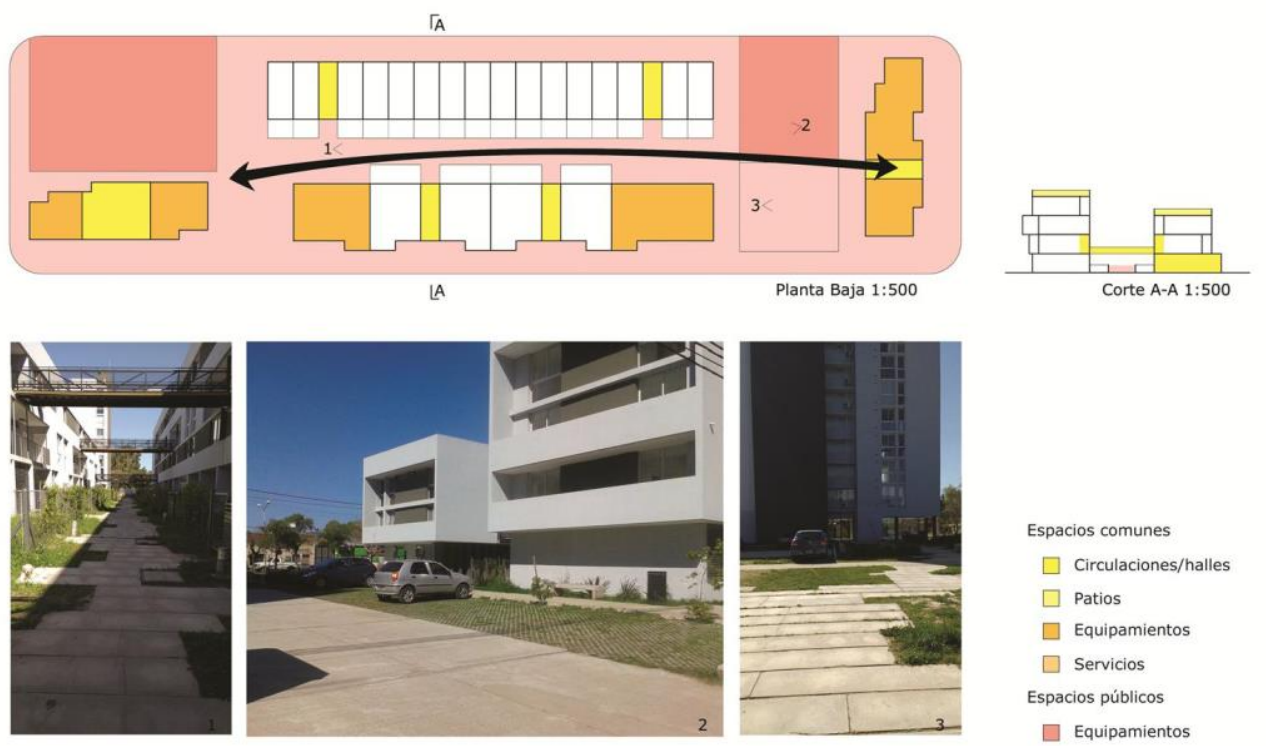
Espacios comunes
$\square$ Circulaciones/halles
$\square$ Patios
$\square$ Equipamientos
$\square$ Servicios
Espacios públicos
$\square$ Equipamientos

$\square$ Espacios abiertos

Fig. 5. Conjunto en Granadero Baigorria - Análisis espacios comunes y públicos: articulaciones Fuente: Camila Benítez, Clara Rovere, Camila Vila; AC-2017 


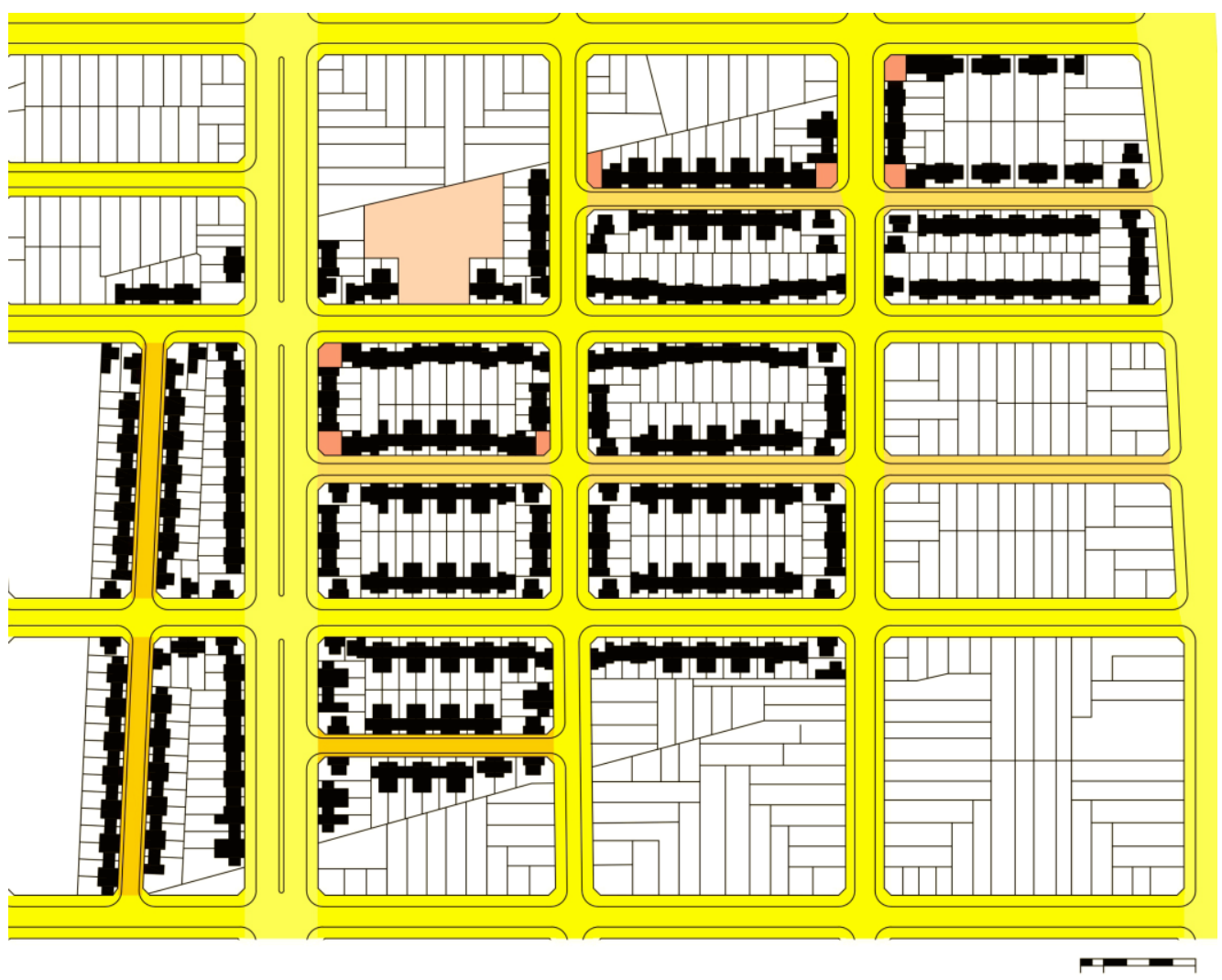

Fig. 6. Barrio Parque - Análisis espacios comunes y públicos: cohabitación

Fuente: Guadalupe Fernández; AC-2017
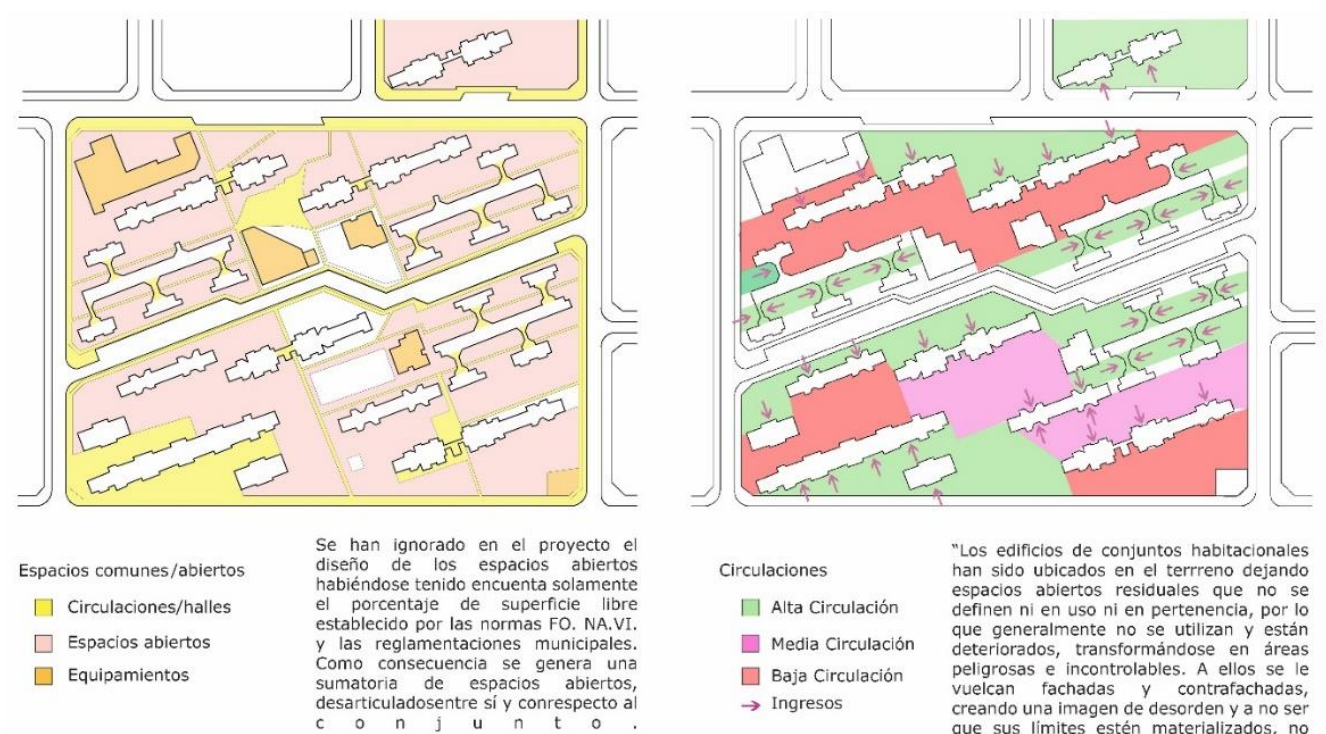
Circulaciones $\quad$ Los edificios de conjuntos habitacionales
espacios ablertos residuales que no se
definen ni en uso ni en pertenencia, por ló
Media Circulación deteriorados, transformándose en áreas
$\square$ Baja Circulación peligrosas e incontrolables. A ellos se le
$\rightarrow$ Ingresos
que sus limites estén materializados, no
pertenecene ni al conjunto ni a la ciudad.

Fig. 7. Barrio Latinoamérica - Análisis espacios comunes y públicos: transiciones barriales

Fuente: Paulo Duzevic, Sara Moreyra; AC-2017 


\subsection{Usos comunitarios}

Entendiendo al hábitat de forma integral más allá de la vivienda, éste debería trascender a sus funciones residenciales para ser capaz de generar en su configuración espacios comunitarios y de albergar otro tipo de actividad que la meramente habitacional. Así, "es importante entender que las viviendas no son ni pueden ser piezas autónomas sobre un tablero de juego. Cuando funcionan, cuando son capaces de favorecer la creación de redes sociales y comunitarias, crean ciudad real y lo hacen sobre las bases de un buen proyecto urbano" (Montaner; Muxí; Falagán, 2010: 45). Por este motivo, se desarrolla el concepto de hábitat productivo como tema central. Pero, más allá de la producción, también se analizan estos espacios desde su posibilidad de cuidados, protección, reunión, esparcimiento, salud, deporte, educación, cultura, alimentación (fig. 8) o consumo (fig. 9), fomentando el encuentro, la puesta en común y las decisiones colectivas; en definitiva, potenciando la micropolítica, como ese eslabón primero de involucración político-social, mostrando la superación de la voluntad individual frente al consenso en las divergencias.

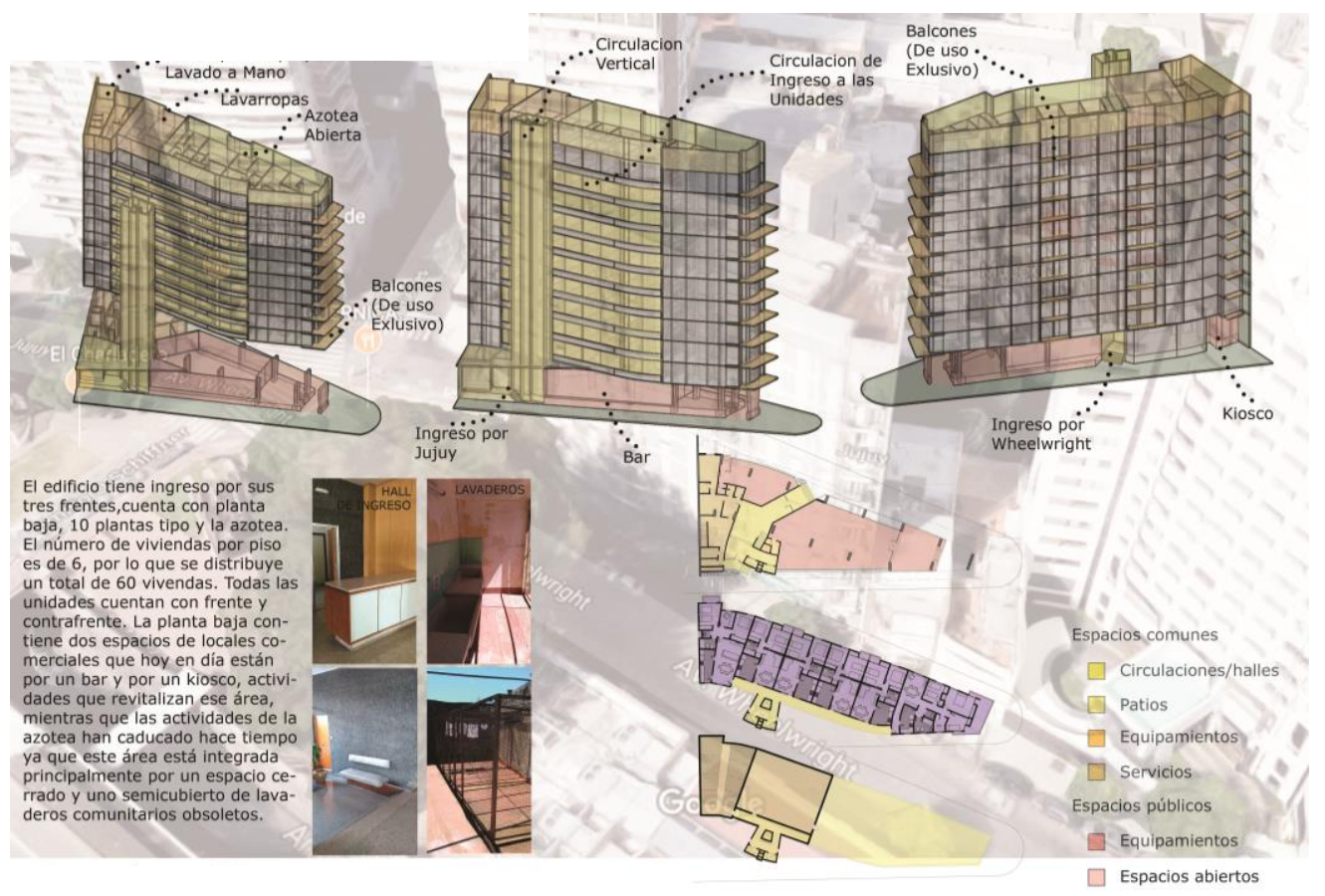

Fig. 8. Edificio Guernica - Análisis espacios comunes y públicos: servicios cooperativos

Fuente: Melanie Schall, Lisi Vesco; AC-2017 


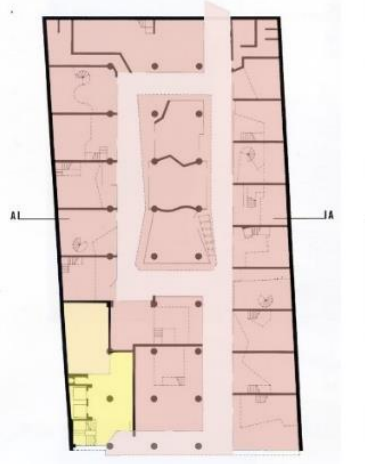

Phata bojip

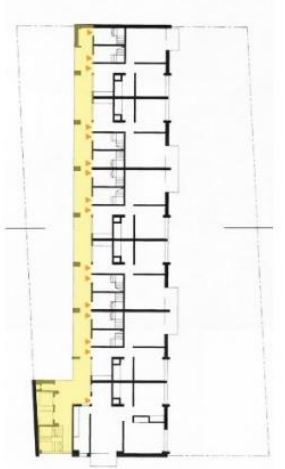

Planta tipo interier

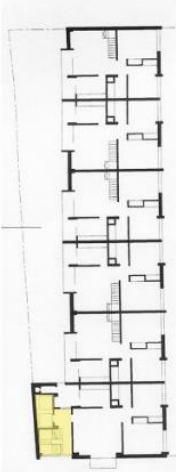

Planta tipospoeior

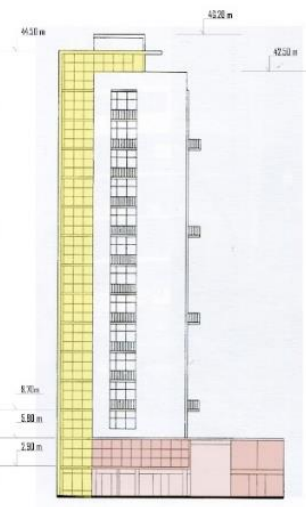

Vsta sit

$$
\begin{aligned}
& \text { Espacios comunes } \\
& \square \text { Circulaciones/halles } \\
& \square \text { Patios } \\
& \text { Espacios públicos } \\
& \square \text { Equipamientos } \\
& \square \text { Circulaciones }
\end{aligned}
$$

Fig. 9. Conjunto Galería César - Análisis espacios comunes y públicos: usos mixtos

Fuente: Carla Beretta, Micaela Notz; AC-2017

\section{ESTRATEGIAS PARA LA COHABITACIÓN}

A partir del paradigma de lo común y lo relacional anteriormente descrito, se plantea realizar algunas propuestas posibles de diseño y planificación del desarrollo urbano, siempre intentando conciliar la cuestión del desarrollo sustentable tanto en términos sociales, como económicos, culturales y ambientales. En este sentido, se proponen a las espacialidades de lo común -en sus dimensiones físico-espaciales, funcionales y de producción y gestión del hábitat- como una oportunidad a seguir explorando formal y simbólicamente mediante sus caracterizaciones posibilitantes, con el fin de potenciar su carácter comunal a través de modificaciones y resignificaciones para su uso como herramienta proyectual.

Así, el objetivo principal de esta parte de la propuesta de trabajo es hacer especial atención a la potencialidad de los espacios comunes como articuladores para la inclusión y como herramientas para la construcción de imaginarios habitacionales alternativos de manera colectiva. Para ello, se delinean algunas estrategias proyectuales de adecuación y/o densificación para la vivienda colectiva contemporánea al paradigma de "Io común", siguiendo ciertos lineamientos de la Nueva Agenda Urbana aplicados a los casos de estudio.

\subsection{Patrones urbanos}

A partir de los espacios comunes podemos pensar estrategias de cambios de patrones urbanos. Teniendo en cuenta las variables de la ocupación del suelo, la altura, la densidad y la compacidad podemos plantear modificaciones al tejido existente; es decir, en casos de baja altura podemos ampliar (fig. 10) o densificar (fig. 11) el tejido y en casos de mucha altura podemos adaptar el conjunto (fig. 12) para disminuir su densidad. Todo ello a partir de los espacios comunes como articuladores. 


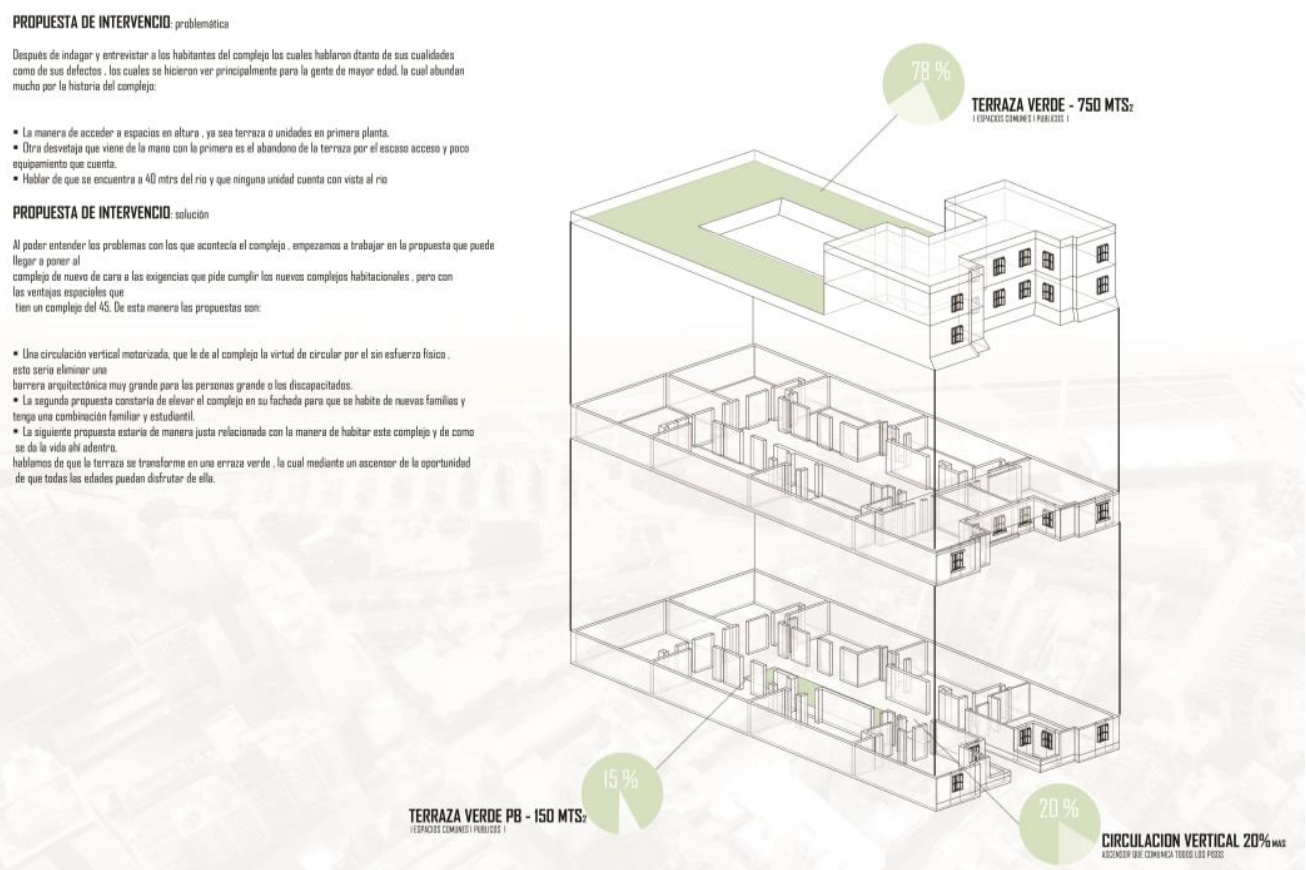

Fig. 10. Conjunto en Tucumán 1048 - Propuesta de intervención: ampliación

Fuente: Santiago Arias, Gastón Chaves, Germán Quinteros; AC-2017

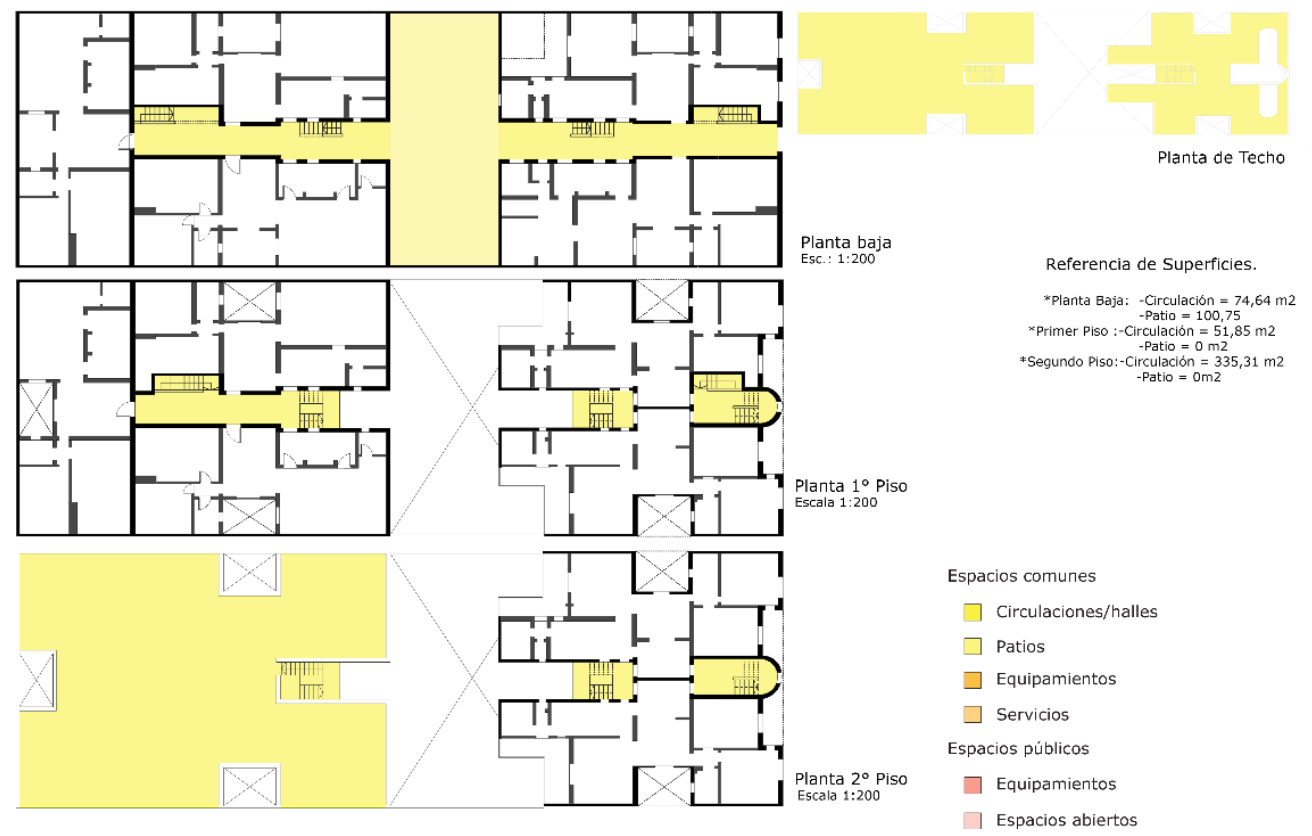

Fig. 11. Conjunto en Oroño 44 bis - Propuesta de intervención: densificación

Fuente: Nahuel Ginart, Nicolás Zof; AC-2017 

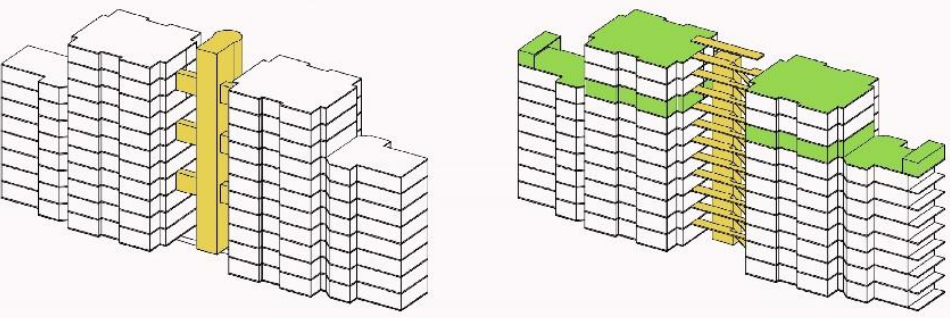
Se interviene sobre circulación vertical de los bloques, ya que los paradas cada 3 pisos
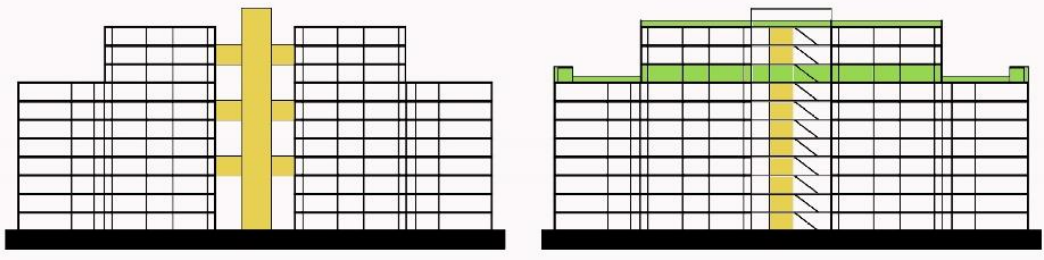

$\square$ Utilización un piso libre con espacios comunes se apovecha el espacio al aire libre para recreación y descanso.

1 La estructura independiente permite de los muros internos, facilitando la transforamcion de los espacios a tal punto que varios departamenos podrian combinarse para ormar uno solo podrian dividirse por ejemplo en 3 . El tipo de planta y las proporciones que maneja permeable para estos cambios teniendo varias posibilidades de

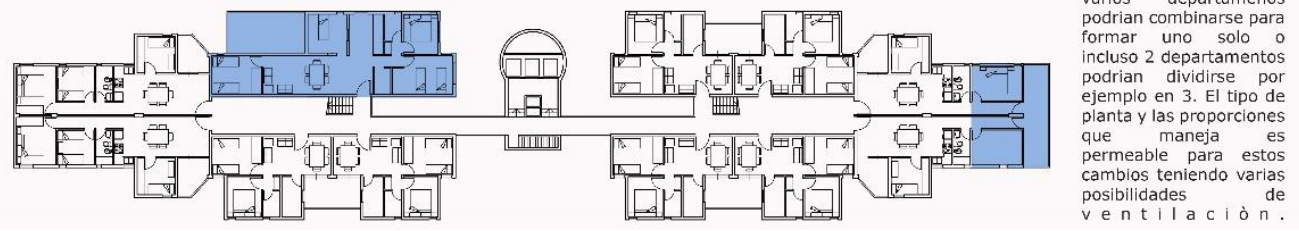

Fig. 12. Barrio Latinoamérica - Propuesta de intervención: flexibilidad

Fuente: Paulo Duzevic, Sara Moreyra; AC-2017

Por otro lado, estas espacialidades también nos permiten potenciar la mixtura de usos (fig. 13) y la diversidad social y de clases sociales, siendo espacialmente importante la incorporación de clases sociales de menores recursos económicos.
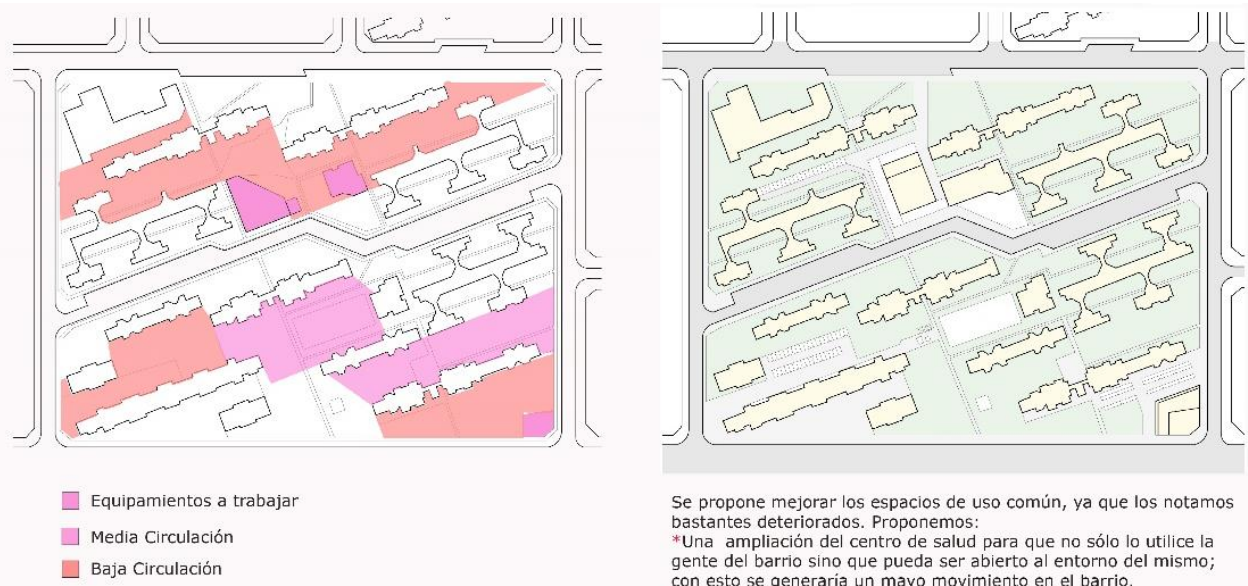

Se propone mejorar los espacios de uso común, ya que los notamos deteriorados. Proponemos:

gente del bacrión del centro de salud para que no sólo lo utilice la con esto se generaria un mayo movimiento en el barrio.

Mejorar la esquina del santa fe servicio ya que genera una espalda a los edificios generando un espacio casi muerto, con una plaza seca con ferias para que los productores del barrio puedan exponer sus productos a la venta.

común, agreagando mesas parrilleros cerca es, bancos en las plazas y mejorar la

Se le binda un lugar de estacion.

carecen de los mismo

Fig. 13. Barrio Latinoamérica - Propuesta de intervención: mixicidad

Fuente: Paulo Duzevic, Sara Moreyra; AC-2017 


\subsection{Resiliencia}

Los espacios comunes nos ayudan a responder a criterios de flexibilidad de las unidades habitativas y de los conjuntos, en relación a la versatilidad de usos y variación en el tiempo, pero también permitiendo explorar adaptaciones posibles para dotar de mayor habitabilidad al tejido (fig. 14). Sirven también para ofrecer reflexiones acerca de las necesidades habitacionales contemporáneas y ayudar a quebrar la relación entre espacio y poder. Así, aparecen estrategias en busca de mayor diversidad y multiplicidad tipológica y habitacional, con la incorporación de nuevas tipologías habitacionales en relación a nuevas estructuras familiares, por ejemplo (fig. 15).
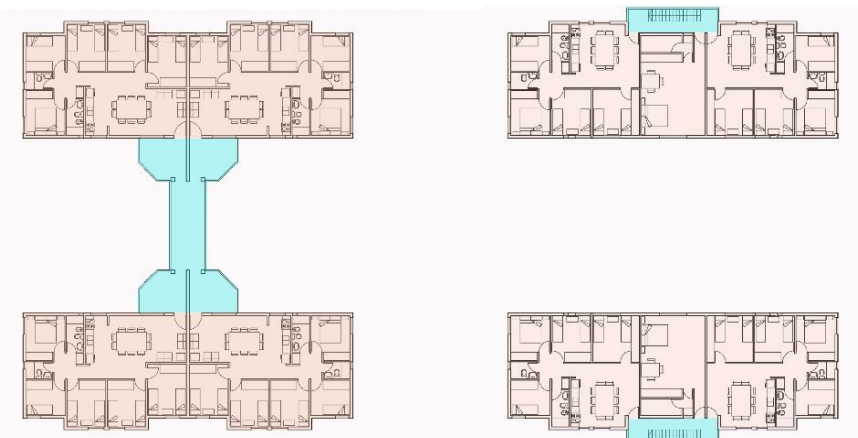

$\square$ Se propone quitar la lograr una reducción de superficie utilizada para circulación y además libera los espacios interiores, lo que permite una mejor

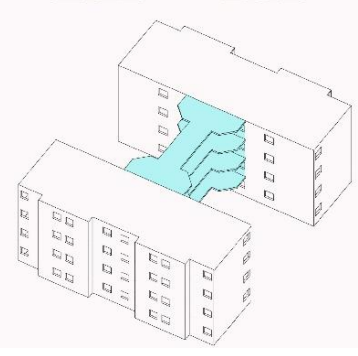

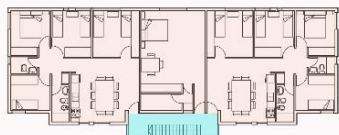

$\square$ De acuerdo al análisis realizado se verifica que las habitaciones se encuentran hacla el exterior en el
conjunto de bloques conjunto de bloques
quedando los espacios de h a b i t a r cocina/comedor hacia el interior, por esta razón se de tal modo que los "estares" facilitando el exterior Iluminación naturaso desde el este como del oeste

Fig. 14. Barrio Latinoamérica - Propuesta de intervención: adecuación

Fuente: Paulo Duzevic, Sara Moreyra; AC-2017
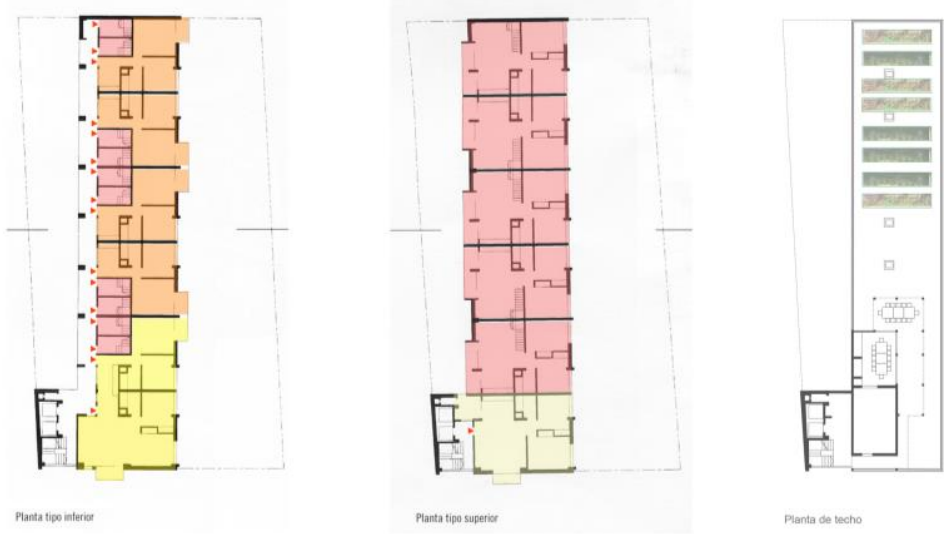

Plantas tipo

$$
\begin{aligned}
& \text { Tipo A. Frentista. } 3 \text { dormitorios. } 107 \mathrm{~m} 2.4 \text { unidades } \\
& \text { Tipo B. Frentista. } 2 \text { dormitorios. } 75 \mathrm{~m} 2.8 \text { unidades } \\
& \text { Tipo C. } 1 \text { dormitorio. } 42 \mathrm{~m} 2.16 \text { unidades } \\
& \text { Tipo D. } 2 \text { dormitorios. } 66 \mathrm{m2} .40 \text { unidades }
\end{aligned}
$$

Fig. 15. Conjunto Galería César - Propuesta de intervención: multiplicidad, producción

Fuente: Carla Beretta, Micaela Notz; AC-2017 
Además, "lo común" permita explorar propuestas que tienden a la autosuficiencia, la adaptación y la accesibilidad, introduciendo espacios productivos comunitarios asociados a la vivienda. Por ejemplo, la incorporación de espacios para la autoproducción de alimentos tipo huertas (fig. 15), o espacios comunes de diferentes usos tal como cocinas, restaurantes y comedores colectivos, talleres, ágoras, coworkings, etc. Siempre con la idea de mejorar la calidad de vida individual con usos de carácter colectivo.

\subsection{Identidad y Patrimonio}

Teniendo en cuenta el capital instalado en el territorio y con el objetivo de preservar las identidades particulares de las comunidades, los espacios comunes pueden ayudar a poner en valor el patrimonio existente gracias a la multiplicidad de usos posibles que posibilitan. Pensar la función a partir de "lo común" es imaginar escenarios alternativos necesarios y deseados por los habitantes de dicha comunidad. A veces, la simple transformación funcional de ciertos espacios podría cambiar las dinámicas de cotidianeidad establecidas en el conjunto (fig. 16), cosa que podría conllevar una mejora en la calidad de vida. Por ejemplo, espacios para los cuidados, para el encuentro, para la ayuda mutua y el diálogo, así como espacios para la recreación o el deporte, pueden servir para regenerar una pieza o un conjunto urbano.

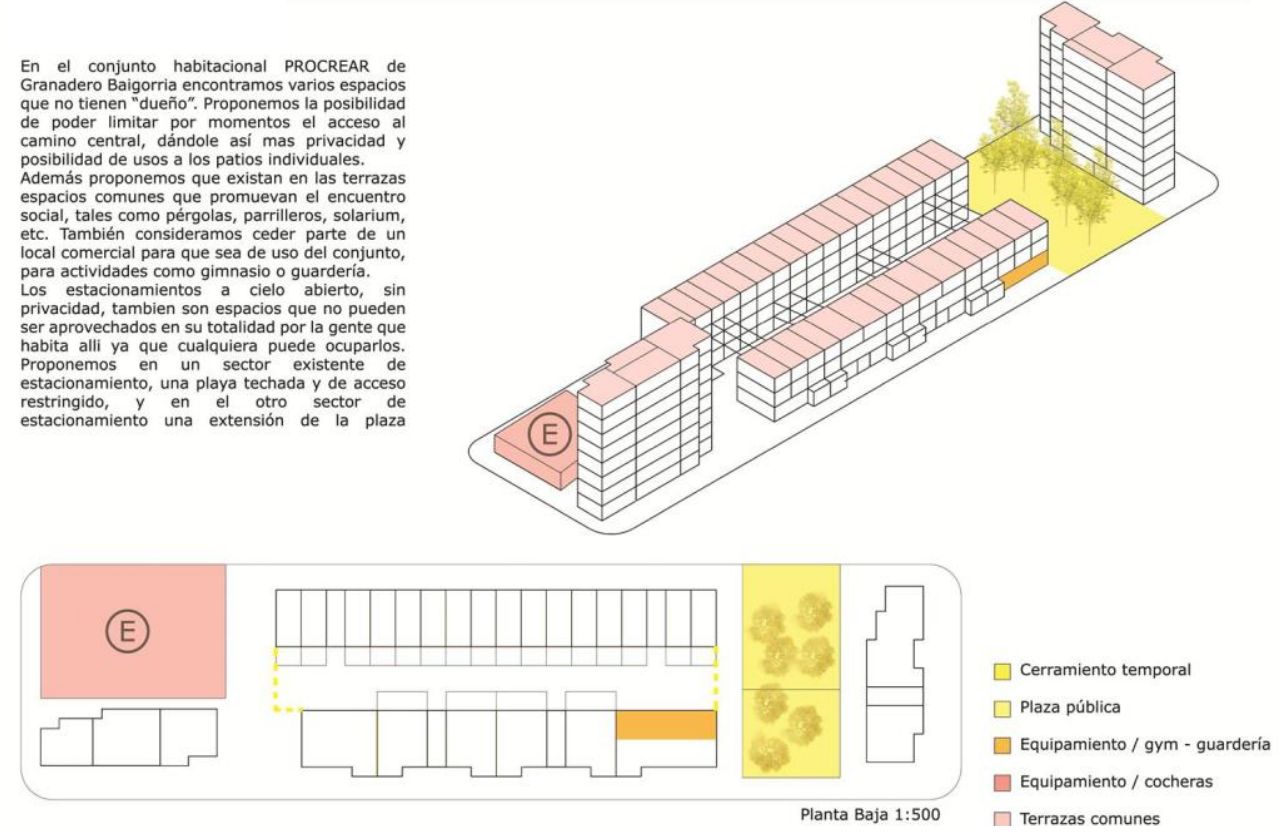

Fig. 16. Conjunto en Granadero Baigorria - Propuesta de intervención: cambio de usos

Fuente: Camila Benítez, Clara Rovere, Camila Vila; AC-2017

La mirada desde "lo común" también sugiere la posibilidad de activar ciertos espacios con el objetivo de colectivizar las actividades que allí se puedan realizar; es decir, pasar un espacio de uso privado a uno comunitario, ya sea a través de una cesión de uso, una restricción al dominio o un reglamento específico en el consorcio, puede potenciar la convivencia y los lazos de contención colectiva (fig. 17). 


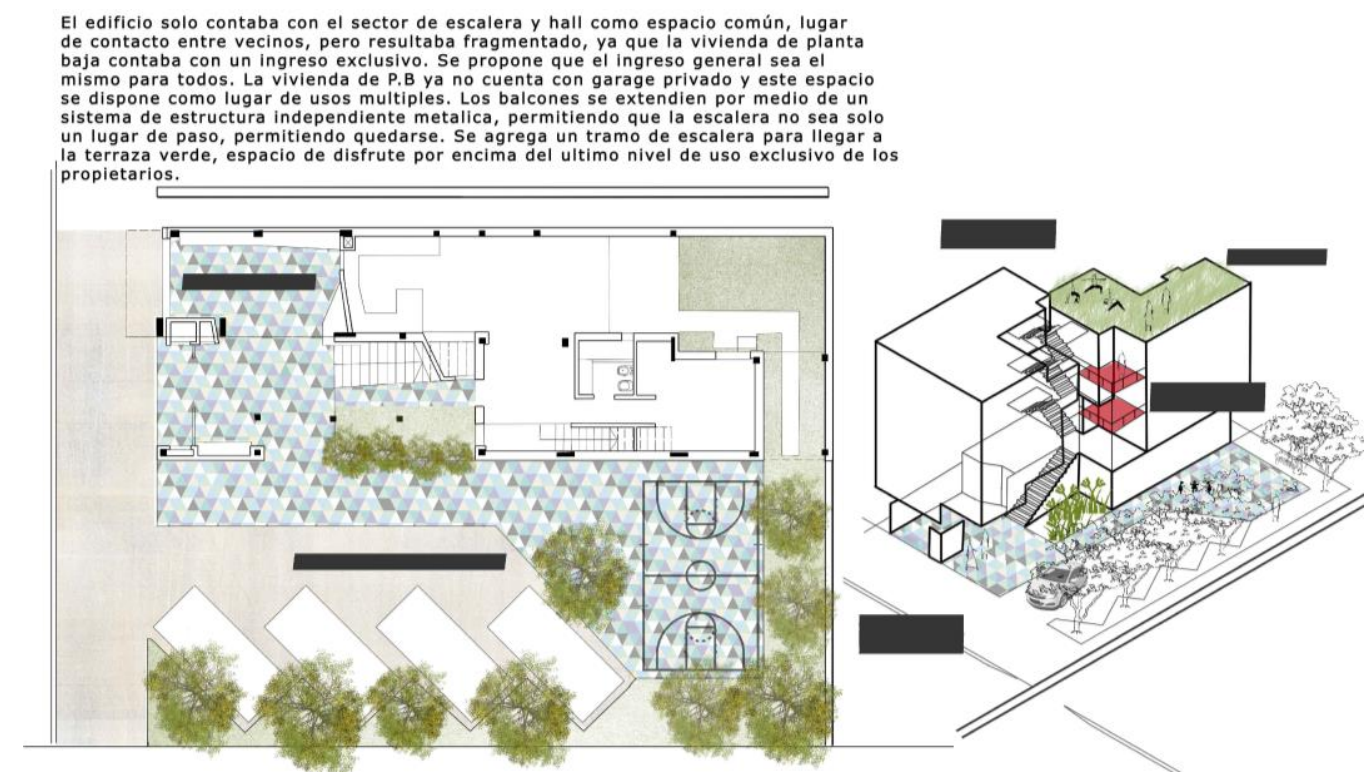

Fig. 17. Conjunto Mandel 1 - Propuesta de intervención: activación

Fuente: Julieta Sadlej, Silvia Segura; AC-2017

\subsection{Financiamiento urbano}

Más allá de aquellos lineamientos de la Nueva Agenda Urbana donde el estudio de los espacios comunes permite explorar mejor estrategias proyectuales de adaptación sobre el tejido existente, el paradigma de "lo común" hacia la construcción de las denominadas "ciudad comunes" también nos ayuda a pensar en temas que tienen más que ver con la producción y gestión del hábitat.

Fomentar el alquiler social y la cesión de uso, mediante la creación de una Inmobiliaria Social, fomentar las cooperativas de viviendas y el cohousing para la renovación urbana, a través planes y financiamientos que los puedan favorecer, o establecer protocolos de trabajo en relación entre el Estado, ONGs y comunidades sobre temas financieros de acceso al hábitat serían temas de abordaje hacia una producción de ciudad más horizontal, equitativa y colaborativa. Se plantea que se puedan ofrecer otras líneas alternativas de acceso al hábitat, que no sean exclusivas de compra y que permitan la producción de la vivienda por parte de la propia comunidad mediante pequeñas o medianas empresas, PYMEs, cooperativas o, incluso, la autoconstrucción guiada.

\subsection{Distribución de inversiones}

Otro de los temas en relación al paradigma de aplicación tiene que ver con las medidas necesarias para fomentar una ciudad en red conectada, abierta y distribuida de manera uniforme y proporcional por el territorio. Trabajar a favor de la descentralización funcional y la distribución de las inversiones y los servicios permitiría reforzar la escala de proximidad, humanizar las dinámicas cotidianas y minimizar las desigualdades en las ciudades a favor de la sustentabilidad urbana deseada.

La regulación del suelo y del mercado inmobiliario es una deuda pendiente en la mayoría de las ciudades mundiales, donde la regulación de departamentos turísticos, de viviendas vacías y lotes en desuso debería ser una medida lógica y urgente a tomar. Por otro lado, sistemas de comercio justo, como herramientas digitales de acceso a la vivienda como plataformas o aplicaciones, deberían potenciarse para su autoregulación, así como proponer medidas para resolver el conflicto de transitoriedad de la vivienda, como necesidad urbana contemporánea determinante. 
Para ello, se proponen unidades de gestión, ejecución, monitoreo y control de manera descentralizada a nivel municipal y metropolitano, que puedan trabajar de manera integral dando cuenta de todos los conflictos y operar en red.

\subsection{Participación y construcción de alianzas}

El fomento de modelos tipo cohousing o cooperativas de vivienda serían opciones interesantes y alternativas de acceso al hábitat todavía muy poco explotadas como mecanismos de producción y gestión de vivienda de manera comunitaria, que permitiría el fomento del empleo de emprendedores pequeños y medios y la auto-organización de la población.

Además, este tipo de producción social del hábitat permitiría un cambio de paradigma en la manera de entender el diseño y la producción de vivienda, puesto que se haría mediante procesos de participación y empoderamiento. Esto permitiría construir canales de participación abiertos, plurales y accesibles y establecer procesos de imaginación y co-diseño a través de los espacios comunes como elementos articuladores y posibilitantes del hábitat colectivo y de su vivencia en común.

\section{CONCLUSIONES}

Los resultados expuestos en el presente trabajo representan un avance en el desarrollo de la tesis de doctorado, según el cronograma establecido. Son todavía exploraciones iniciales en la temática, pero pretenden ir dando sentido y formato a la propia tesis. Por el momento, se puede asegurar que la introducción de la dimensión de "lo común" a la formación académica plantea nuevos caminos de exploración. El análisis a partir de las espacialidad de lo común permite una reflexión más profunda sobre el hábitat contemporáneo y plantea incluso la posibilidad de esbozar estrategias proyectuales alternativas a partir de ellos.

Durante el próximo curso se prevé explorar más casos y ampliar el recorte de exploración. Así, para la ciudad de Rosario se plantea seguir con nuevos casos dentro de la materia optativa en la Facultad de Arquitectura, Planeamiento y Diseño de la Universidad Nacional de Rosario (FAPyD-UNR). Y también se suma la ciudad de Buenos Aires como territorio a explorar, mediante el proyecto de investigación PIT PyH-04 "La Ciudad Común: la vivienda popular colectiva como germen de una urbanidad alternativa desde el territorio latinoamericano", dentro del programa de acreditación institucional de proyectos de investigación de la Secretaría de Investigación de la Facultad de Arquitectura, Diseño y Urbanismo de la Universidad de Buenos Aires (FADU-UBA).

La idea es ir sumando casos de análisis diversos con el objetivo de conformar un repositorio abierto de planos de vivienda colectiva con el objetivo de generar una herramienta digital de apoyo al diseño urbano-arquitectónico. La creación del repositorio constituye la base de un proyecto en desarrollo paralelamente llamado HabitatFabrik, que propone ofrecer una "caja de herramientas" y cuyo objetivo es democratizar el acceso al diseño y fomentar procesos colaborativos de co-diseño y co-construcción del hábitat.

Se plantea además, para 2018, mejorar los análisis, las representaciones y las propuestas proyectuales profundizando sobre los casos, teniendo como parámetros de análisis: espacialidad, sujeto, uso, producción y gestión de "lo común".

\section{BIBLIOGRAFÍA}

BORJA, J. (2015), La vivienda popular, de la marginación a la ciudadanía (Parte I), en: http://www.plataformaurbana.cl/archive/2015/12/30/la-vivienda-popular-de-la-marginacion-a-la-ciudadania-partei-por-jordi-borja/ (consultado el 18.03.16).

FRANCO, V. (2016a), "La ciudad común. La vivienda popular colectiva como germen de una urbanidad alternativa desde el territorio latinoamericano", en Actas del V Congreso Latinoamericano de Derechos Humanos (Rosario: UNR). 
_ (2016b), "Paisajes urbanos emergentes. De las crisis sistémicas a la era de las ciudades por el bien común", en Revista A\&P Continuidad, n 5 (Rosario: Editorial FAPyD-UNR).

_ (2017a), "Paisajes y espacios comunes en el hábitat popular colectivo. El tejido urbano-habitacional de departamentos de pasillo y pasajes en Palermo (Buenos Aires), en Actas del IX Seminario Internacional de Investigación en Urbanismo (Barcelona: ETSAB-UPC).

_ (2017b), "El hábitat como proceso y los espacios comunes como resistencia", en Actas del V Congreso İberoamericano de Teoría del Habitar "(SUB)URBANO. Habitar con justicia espacial” (San Justo: UNLaM).

GARNIER, J-P. (2006), Contra los territorios del poder: por un espacio público de debates y... de combates, Barcelona, Virus.

GUTIÉRREZ, B. (2016), "Habitar las ciudades democráticas", en Diagonal Periódico. Disponible en: https://www.diagonalperiodico.net/saberes/31116-habitar-ciudades-democraticas.html (consultado el 16.08.14).

HARVEY, D. (1977), Urbanismo y desigualdad social, Madrid, Siglo XXI [ed. orig.: Social Justice and the City, London, Edward Arnold, 1973].

_ (2008), "El derecho a la ciudad", en New Left Review, no 53 (noviembre-diciembre), Madrid, Akal, en: http://www.universidadnomada.net/spip.php?article295 (consultado el 20.04.11).

LAVAL, C.; DARDOT, P. (2014), Commun (Paris: Éditions La Découverte) [ed. cast. 2015. Común. Ensayo sobre la revolución en el siglo XXI (Barcelona: Gedisa)].

MONTANER, J. M.; MUXÍ, Z.; FALAGAN, D. (2010), "Herramientas para habitar el presente. La vivienda del siglo XXI", en Máster Laboratorio de la vivienda del siglo XXI, Barcelona, Editorial UPC.

MUXÍ, Z. (2010), "Revisar y repensar el habitar contemporáneo", en Revista Iberoamericana de Urbanismo, Barcelona.

SÁEZ, E.; GARCÍA, J.; ROCH, F. (2010), "La ciudad desde la casa: ciudades espontáneas en Lima”, en Revista INVI, Santiago de Chile.

SANTIAGO, R. (2010), "El concepto de ciudadanía en el comunitarismo", en Cuestiones constitucionales - Revista mexicana de derecho constitucional, $n^{\circ} 23$ (Ciudad de México: Editorial UNAM).

SASSEN, S. (2001), "The City: Between Topographic Representation and Spatialized Power Projects", en Art Journal, v. 60, no 2, College Art Association.

SOLÀ-MORALES, I. (2009), "Terrain vague" en Iñaki Ábalos (ed.), Naturaleza y artificio: el ideal pintoresco en la Arquitectura y el Paisajismo contemporáneos (Barcelona: Editorial Gustavo Gili).

SUBIRATS, J.; MONTANER, J. M. (2012), Repensar las políticas urbanas (Barcelona: Diputació de Barcelona). 